\title{
Polymorphisms in the interleukin-10 gene and relation to phenotype in patients with ulcerative colitis
}

\author{
J. L. Mendoza, E. Urcelay ${ }^{1}$, R. Lana ${ }^{2}$, A. Martínez ${ }^{1}$, C. Taxonera, E. G. de la Concha ${ }^{1}$ and M. Díaz-Rubio \\ Departments of Gastroenterology, ${ }^{I}$ Immunology and ${ }^{2}$ Emergency Medicine. Hospital Clínico San Carlos. Universidad \\ Complutense. Madrid, Spain
}

\begin{abstract}
Background and objectives: interleukin-10 (IL-10) has a key role in regulating mucosal inflammation in inflammatory bowel disease. In our population of Spanish ulcerative colitis (UC) patients, we have previously demostrated that two polymorphisms (IL-10.G14 microsatellite allele and homozygous for the $-1082 \mathrm{G}$ alelle (guanine at position -1082)) in the IL-10 gene were susceptibility markers for disease. No data exist regarding the relationship of these IL-10 polymorphims with phenotypic subpopulations in UC. Therefore, this study sought to examine the contribution of IL-10 polymorphims to phenotypical variability in UC.

Material and methods: a cohort of 215 Spanish unrelated patients with UC recruited in a single center was studied. All patients were rigorously phenotyped and followed for at least 3 years (mean time: 11.8 years). The clinical phenotype was established before genotyping. Genotyping was performed using polymerase chain reaction (PCR) assays.

Results: patiens with UC included 129 (60\%) men and 89 (40\%) women. Mean age at diagnosis was 38 years, with a range of 8-83. Disease extent included 127 (59.1\%) left-side patients and 88 (40.9\%) extensive patients. Neither UC phenotype variable was associated with the presence of susceptibility polymorphims (10G14 microsatellite and -1082G alelle).

Conclusions: in Madrid's Spanish population of UC patients, the carrying of the ILG14 microsatellite or $-1082 \mathrm{G}$ polymorphism in the IL-10 gene was not associated with phenotype of disease.
\end{abstract}

Key words: Ulcerative colitis. Interleukin-10 gene. Phenotype. Inflammatory bowel disease.

Mendoza JL, Urcelay E, Lana $R$, Martínez A, Taxonera $C$, de la Concha EG, Díaz-Rubio M. Polymorphisms in the interleukin-10 gene and relation to phenotype in patients with ulcerative colitis. Rev Esp Enferm Dig 2006; 98: 93-100.

Recibido: 06-05-05.

Aceptado: 04-10-05.

Correspondencia: Juan Luis Mendoza. Servicio de Aparato Digestivo (Prof. Díaz-Rubio). Unidad de Enfermedad Inflamatoria Intestinal. Hospital Clínico San Carlos. C/ Martín Lagos, s/n. 28040 Madrid. Fax: 913303 785. e-mail: jmendozah@meditex.es

\begin{abstract}
ABBREVIATIONS
UC: ulcerative colitis; CD: Crohn's disease; IBD: inflammatory bowel disease; IL-10: interleukin-10; IFN- $\gamma$ : interferon-gamma; PRC: polymerase chain reaction; SNP: single nucleotide polymorphism; TNF: tumor necrosis factor.
\end{abstract}

\section{INTRODUCTION}

Ulcerative colitis (UC) is an inflammatory bowel disease (IBD) that only affects the colonic mucosa. The symptoms and severity of this disease will depend on the extension, inflammatory grade, and activity of the extraintestinal manifestations associated, aspects conferring a significant clinical heterogeneity.

The etiopathogenesis of this disease remains poorly understood. Experimental and observational data suggest that intestinal inflammation arises from abnormal immune reactivity to bacterial flora in the intestine of individuals who are genetically susceptible (1).

Epidemiologic and linkage studies suggest that genetic factors play a significant role in establishing UC susceptibility. UC has no simple Mendelian pattern of inheritance (2). As other immune diseases, UC is thought to be a heterogeneous, complex polygenic disease where both genetic and environmental factors play an important role in the disease, and in which multiple interactions between susceptibility and resistance alleles are involved in its pathogenesis (3).

Human genetic studies, notably the landmark identification within the IBD3 linkage region, have confirmed a genetic influence on UC. The IBD3 "locus" encompasses the major histocompatibility complex $(\mathrm{MCH})$ region on chromosome 6 (6q), which contains over 200 genes. An association between genes in the major histocompatibili- 
ty complex (MHC), particularly HLA genes (class I and II), and UC has been repeatedly described. Although most studies have focused on HLA class II genes, there is interest in the role of cytokines in UC pathogenesis, and in the polymorphic genes that may influence cytokine secretion $(4,5)$.

The most consistently described associations have been between UC and HLA-class II alleles, especially with HLA-DR2 (6) and HLA-DRB1*0103. Two subtypes of DR2, DRB1*1501 and DRB1*1502, have been associated with disease or disease extension in different populations (7). The rare DRB $1 * 0103$ allele has been repeatedly associated with disease susceptibility, extensive disease, more severe forms of disease, and extraintestinal manifestations (8).

A variety of genes coding for various proteins involved in immune regulation have been postulated as possible candidates to disease susceptibility genes, including cytokines such as interleukin-10 (IL-10) among others. IL-10 is a regulatory cytokine with several functions (9). Recently, we have also shown that IL-10 polymorphisms contribute to susceptibility in Crohn's disease (CD) and UC in our Spanish population (10). As IL-10 polymorphisms appear to confer a higher risk for IBD in the Spanish population, the present study examines genotype-phenotype correlations in UC.

\section{MATERIAL AND METHODS}

\section{Study population}

We studied a cohort of 215 Caucasian unrelated consecutive patients with UC who were recruited in the Unit of Inflammatory Bowel Disease (IBD) of a single tertiary referral center (Hospital Clínico San Carlos) in Madrid, Spain. The diagnosis of UC was based on standard clinical, radiographic, endoscopic, and histologic criteria (11). Phenotypic details were obtained by reviewing clinical charts and through personal interviews with patients. A surgical procedure was recorded when colectomy was indicated in patients intractable with medical therapy, and for those with massive hemorrhage, colonic perforation, and unresolving toxic megacolon. Disease distribution was simplified into two groups: extensive UC, meaning those with total or subtotal colitis (beyond the splenic flexure), and non-extensive disease, meaning disease limited to the left colon, including patients with left colitis, proctosigmoiditis, and proctitis. The distribution was assessed both macroscopically and microscopically at the time of diagnosis and at subsequent colonoscopies. The maximum extent recorded was used in the qualification for this study. All patient data were recorded by an IBD Unit gastroenterologist who was blinded to patient genotype status.

\section{Genotyping}

Regarding IL-10 polymorphisms, IL-10G and IL-10R microsatellites were amplified using primers and conditions previously described (12). Blood samples were subsequently denatured and processed by an ABI Prism 3100 automatic sequencer (Applied Biosystems, Foster City, CA, USA). Each sample included an internal size standard (HD400 ROX, Applied Biosystems) in order to achieve a highly consistent measure. Results were analyzed using GeneMapper v3.0 (Applied Biosystems).

As previously described (13), a combined amplification of IL-10G microsatellite and both -1082 and -819 SNPs was performed. Our typing method allowed direct haplotype construction.

\section{Statistical analysis}

Nominal variables were summarized according to their frequencies distribution. Ordinal variables were summarized using their mean and range values. IL-10 polymorphism frequencies in UC patients were compared using the $\chi^{2}$ test or Fisher's exact test when the expected value was less than $5 ; \mathrm{p}$ values were considered significant when $<0.05$. Odds ratio $(\mathrm{OR})$ and $\mathrm{p}$ values were calculated using the Statistical Package for Social Sciences (SPSS), version 10.07 for Windows (SPSS Inc., Chicago, Ill. USA).

\section{RESULTS}

Our cohort of 215 patients with UC included 129 $(60 \%)$ men and $86(40 \%)$ women. Mean age at diagnosis was 35 years (range 10-78) in men, and 38 years (range $3-42$ ) in women. The mean duration of follow-up was 11.8 years (range 3-42). Disease distribution for UC patients was extensive in $88(40.9 \%)$ and non-extensive in $127(59.1 \%)$.

Genotype-phenotype correlations are shown in tables I and II. Neither disease extension, nor risk factors, clinical manifestations, or treatment modalites were associated with either IL-10.G14 or -1082G/G alleles.

\section{DISCUSSION}

IL-10 is a regulatory cytokine that has several functions; one important role is to act as an inhibitor of the development of Th1 cells, activated macrophages, and their products -interleukin-12 (IL-12), tumor necrosis factor (TNF), and interferon-gamma (IFN- $\gamma$ ). Even though usually considered an inhibitory cytokine, it also has stimulating effects (e.g. B-cell proliferation) (9). However, the biology of IL-10 is highly complex. In addition to a down-regulation of immunity, both human 
Table I. Phenotypic frequencies of IL10G14 microsatellite in ulcerative colitis patients

\begin{tabular}{|c|c|c|c|}
\hline Phenotypic characteristics & $\begin{array}{c}I L-10 . G 14(-) \\
n^{\circ}=177\end{array}$ & $\begin{array}{c}\text { IL-10.G14(+) } \\
n^{\circ}=38\end{array}$ & $p$ \\
\hline Male: female & $106: 71$ & $23: 15$ & 1 \\
\hline Mean age at diagnosis, years (range) & $38(12-78)$ & $37(8-83)$ & 0.42 \\
\hline Mean duration of disease, years (range) & $12.4(3-39)$ & $11.3(3-42)$ & 0.5 \\
\hline Family history of IBD, no. (\%) & $44(27.4 \%)$ & $4(10.5 \%)$ & 0.083 \\
\hline Smokers at diagnosis, no. (\%) & $39(21.9 \%)$ & $13(34.2 \%)$ & 0.1 \\
\hline Previous appendectomy, no. (\%) & $8(4.5 \%)$ & $3(7.9 \%)$ & 0.41 \\
\hline Previous tonsillectomy, no. (\%) & $22(12.4 \%)$ & $2(5.3 \%)$ & 0.2 \\
\hline \multicolumn{4}{|l|}{ Extent of UC } \\
\hline Extensive, no. (\%) & $68(38.4 \%)$ & $20(52.6 \%)$ & 0.1 \\
\hline Non-extensive, no. (\%) & $109(61.6 \%)$ & $18(47.4 \%)$ & \\
\hline \multicolumn{4}{|l|}{ Extraintestinal clinical manifestations } \\
\hline Cutaneous, no. (\%) & $23(12.9 \%)$ & $6(15.8 \%)$ & 0.6 \\
\hline Articular, no. (\%) & $59(33.1 \%)$ & $14(36.8 \%)$ & 0.7 \\
\hline Ocular, no. (\%) & $7(3.9 \%)$ & $0(0 \%)$ & 0.7 \\
\hline Hepatic, no. (\%) & $32(18 \%)$ & $9(23.7 \%)$ & 0.42 \\
\hline \multicolumn{4}{|l|}{ Treatment } \\
\hline Immunosuppressants, no. (\%) & $29(16.3 \%)$ & $7(18.4 \%)$ & 0.81 \\
\hline Surgical procedures, no. (\%) & $17(9.6 \%)$ & $5(13.2 \%)$ & 0.6 \\
\hline
\end{tabular}

Interleukin-10 (IL-10); ulcerative colitis (UC); number (no.); percentage (\%).

Table II. Phenotypic frequencies of -1082 polymorphism in homozygous (G/G) and heterozygous (G/A) or homozygous (A/A) UC patients

\begin{tabular}{|c|c|c|c|}
\hline Phenotypic characteristics & $\begin{array}{c}\text { IL-10 -1082 } \\
\text { G/A y A/A } \\
n^{\circ}=163\end{array}$ & $\begin{array}{c}I L-10-1082 \\
G / G \\
n^{\circ}=52\end{array}$ & $p$ \\
\hline Male: female & $94: 69$ & $17: 35$ & 0.25 \\
\hline Mean duration of disease, years (range) & $11.7(3-38)$ & $12.3(3-42)$ & 0.6 \\
\hline Family history of IBD, no. (\%) & $36(22.1 \%)$ & $12(22.6 \%)$ & 1 \\
\hline Smokers at diagnosis, no. (\%) & $39(23.9 \%)$ & $13(24.5 \%)$ & 1 \\
\hline \multicolumn{4}{|l|}{ Extent of UC } \\
\hline Extensive, no. (\%) & $62(38 \%)$ & $26(49.1 \%)$ & 0.1 \\
\hline Non-extensive, no. (\%) & $101(62 \%)$ & $26(50.9 \%)$ & \\
\hline \multicolumn{4}{|l|}{ Extraintestinal clinical manifestations } \\
\hline Cutaneous, no. (\%) & $25(15.3 \%)$ & $4(7.5 \%)$ & 0.2 \\
\hline Articular, no. (\%) & $54(33.1 \%)$ & $19(26 \%)$ & 0.7 \\
\hline Surgical procedures, no. (\%) & $16(9.8 \%)$ & $6(11.3 \%)$ & 0.8 \\
\hline
\end{tabular}

Interleukin-10 (IL-10); ulcerative colitis (UC); number (no.); percentage (\%).

IL-10 and murine IL-10 exert immunostimulating effects by up-regulating MHC class II expression on B lymphocytes, and inducing cytotoxic T-cell differentiation and increased immunoglobulin production (14).

The therapeutic experience with IL-10 in animal models of colitis is very encouraging. IL-10-knockout mice develop chronic enterocolitis similar to $\mathrm{CD}$, and these mice respond to monoclonal antibody treatment, as is the case with IBD patients. Consistent with this, there have been preliminary reports of clinical symptom relief in CD following the administration of human recombinant IL-10 (rhuIL-10). Unfortunately, enthusiasm was dampened by the results of two multinational, multicenter studies reporting on the efficacy and safety of daily subcutaneous injections of rhuIL-10. However, it is possible that response to IL-10 is limited to a subgroup of patients. 
Recently, some novel alternative approaches, including the use of genetically modified Lactococcus lactis, IL10 -containing gelatine microspheres, adenoviral vectors coding for IL-10, and combining regulatory T cells, may ensure a truly local, tissue-specific and therapeutic delivery of IL-10 (14).

The IL-10 gene is located on the long arm of chromosome 1. Three single basepair substitutions have been identified: $-1082,-812$ and -592 upstream of the transcriptional start site, and two microsatellite loci -IL10.G and IL10.R. In caucasians, the possibility of IL-10 mutation has led to studies with different results (15-18). Recently, we performed an association analysis of IL-10 polymorphisms (microsatellites and promoter SNPs) in a large sample size of Spanish patients with IBD. Our data showed an association between CD and 2 alleles: the IL-10.G14 microsatellite allele and the $-1082 \mathrm{G}$ allele in the IL-10 gene promoter region. Our major finding in this study was that the combined presence of both alleles in an individual notably increased the risk for $\mathrm{CD}$. Interestingly, a similar but weaker effect was observed in patients with UC (IL10.G14 microsatellite and homozygous -1082 G/G) (10). Studies have shown an association with a reduced frequency of the $-1082 \mathrm{G}$ allele in patients with IBD, particularly UC. This was accompanied by a reduced frequency of the homozygous $-1082 \mathrm{G} / \mathrm{G}$ high IL-10 producer genotype in UC patients, and an increase in the homozygous -1082A/A low IL-10 producer genotype in UC $(16,19)$. UC is associated with a relative excess of Th- 2 cytokines, including IL-10. A study demonstrated a differential expression of surface markers on cells infiltrated in the colonic mucosa of UC patients, with a Th-2 polarized response in ulcer margins, suggesting that a Th-1/Th-2 imbalance might be responsible for disease progression. Hence, IL-10 may be critical in determining an individual's susceptibility to UC, as well as its clinical phenotype with regard to extent of disease (18). In this study, this has not been proved.

This study has shown that in Madrid's Spanish population polymorphisms in the IL-10 gene contribute to UC susceptibility, but not to the establishment of any diseasespecific phenotype. A molecular classification of UC will be required in the future.

\section{REFERENCES}

1. Morahan G, Morel L. Genetics of autoimmune diseases in humans and in animal models. Curr Opin Immunol 2002; 14: 803-11.

2. Cho J. Update on inflammatory bowel disease genetics. Curr Gastroenterol Rep 2000; 2: 434-9.

3. Fiocchi C. Inflammatory bowel disease: etiology and pathogenesis. Gastroenterology 1998; 115: 182-205.

4. Ahmad T, Tamboli CP, Jewell D, Colombel JF. Clinical relevance of advances in genetics and pharmacogenetics of IBD. Gastroenterology 2004; 126: 1533-49.

5. Fernández L, Mendoza JL, Martínez A, Urcelay E, Fernández-Arquero M, García-Paredes J, et al. IBD1 and IBD3 Determine Location of Crohn's Disease in the Spanish Population. Inflamm Bowel Dis 2004; 10: 715-22.

6. Fernández Arquero M, López-Nava G, De la Concha EG, Figueredo MA, Santa Cruz S, Dumitru CG, et al. HLA-DR2 gene and Spanish patients with ulcerative colitis. Rev Esp Enferm Dig 1998; 90: 243-9.

7. Fernández-Arquero M, López-Nava G, García Paredes J, Martínez A, De la Concha EG, Figueredo MA, et al. Pancolitis and genetic markers in the Spanish population. Rev Esp Enferm Dig 1999; 91: 269 76.

8. Roussomoustakaki MSJ, Welsh K, Louis E, Fanning G, Targan S, Landers C, et al. Genetic markers may predict disease behavior in patients with ulcerative colitis. Gastroenterology 1997; 112: 1845-53.

9. Mocellin S, Panelli MC, Wang E, Nagorsen D, Marincola FM. The dual role of IL-10. Trends Immunol 2003; 24: 36-43.

10. Fernández L, Martínez A, Mendoza JL, Urcelay E, Fernández-Arquero M, García-Paredes J, et al. Interleukin-10 polymorphisms in IBD Spanish patients. Inflamm Bowel Dis 2005; 10: 715-22.

11. Lennard-Jones JE. Classification of inflammatory bowel disease. Scand J Gastroenterol Suppl 1989; 170: 2-6; discussion 16-9.

12. Eskdale J, Wordsworth P, Bowman S, Field M, Gallagher G. Association between polymorphisms at the human IL-10 locus and systemic lupus erythematosus. Tissue Antigens 1997; 49: 635-9.

13. Eskdale J, Gallagher G, Verweij CL, Keijsers V, Westendorp RG, Huizinga TW. Interleukin 10 secretion in relation to human IL-10 locus haplotypes. Proc Natl Acad Sci U S A 1998; 95: 9465-70.

14. Li MC, He SH. IL-10 and its related cytokines for treatment of in flammatory bowel disease. World J Gastroenterol 2004; 10: 620-5.

15. Parkes M, Satsangi J, Jewell D. Contribution of the IL-2 and IL-10 genes to inflammatory bowel disease (IBD) susceptibility. Clin Exp Immunol 1998; 113: 28-32.

16. Tagore A, Gonsalkorale WM, Pravica V, Hajeer AH, McMahon R, Whorwell PJ, et al. Interleukin-10 (IL-10) genotypes in inflammatory bowel disease. Tissue Antigens 1999; 54: 386-90.

17. Klein W, Tromm A, Griga T, Fricke H, Folwaczny C, Hocke M, et al. The IL-10 gene is not involved in the predisposition to inflammatory bowel disease. Electrophoresis 2000; 21: 3578-82.

18. Aithal GP, Craggs A, Day CP, Welfare M, Daly AK, Mansfield JC, et al. Role of polymorphisms in the interleukin-10 gene in determining disease susceptibility and phenotype in inflamatory bowel disease. Dig Dis Sci. 2001; 46: 1520-5.

19. van der Linde K, Boor PP, Sandkuijl LA, Meijssen MA, Savelkoul HF, Wilson JH, et al. A Gly15Arg mutation in the interleukin-10 gene reduces secretion of interleukin-10 in Crohn disease. Scand J Gastroenterol 2003; 38: 611-7. 